\title{
Prevalence of Cardiovascular Risk Factors among Tile and Ceramic Workers in Yazd, Iran
}

\author{
Amir Houshang Mehrparvar, ${ }^{1}$ Seyyed Jalil Mirmohammadi, ${ }^{1}$ \\ Mehrdad Mostaghaci, ${ }^{1}$ Maryam Bahaloo, ${ }^{2}$ Mohammad Heydari, ${ }^{1}$ Ehsan Samimi, ${ }^{2}$ \\ Mahnaz Zohal, ${ }^{3}$ and Mohammad Hossein Davari ${ }^{1}$ \\ ${ }^{1}$ Department of Occupational Medicine, School of Medicine, Shahid Sadoughi University of Medical Sciences, \\ Shahid Rahnemoun Hospital, Farrokhi Avenue, Yazd 89138-14389, Iran \\ ${ }^{2}$ Industrial Disease Research Center, Shahid Sadoughi University of Medical Sciences, Shahid Rahnemoun Hospital, \\ Farrokhi Avenue, Yazd 89138-14389, Iran \\ ${ }^{3}$ School of Medicine, Shahid Sadoughi University of Medical Sciences, Shahid Rahnemoun Hospital, Farrokhi Avenue, \\ Yazd 89138-14389, Iran
}

Correspondence should be addressed to Mohammad Hossein Davari; drmhdavari@gmail.com

Received 15 September 2013; Accepted 11 November 2013

Academic Editors: K. J. Coleman and S. Glisic

Copyright (C) 2013 Amir Houshang Mehrparvar et al. This is an open access article distributed under the Creative Commons Attribution License, which permits unrestricted use, distribution, and reproduction in any medium, provided the original work is properly cited.

\begin{abstract}
Introduction. Cardiovascular disorders (CVDs) are among the most important diseases in the world and determination of their risk factors is essential for primary and secondary prevention. This study aimed to evaluate these risk factors in workers of tile and ceramic industry, a main industry in Yazd. Materials and Methods. In a cross-sectional study, 1075 tile and ceramic workers were selected by simple sampling method. BMI, blood pressure, FBS, and lipid profile were measured and compared to international standards. Results. 731 individuals (68\%) had at least one risk factor, and 52\%, 12\%, 3\%, and $0.7 \%$ had one, two, three, and four risk factors, respectively. The most common risk factor was abnormal BMI (49.6\%); low HDL (48.4\%) and high TG (14.1\%) were in the second and third orders. Conclusion. This study showed a relatively high prevalence for CVD risk factors among tile and ceramic workers. Low HDL, high TG, and overweight were the most frequent risk factors in this population.
\end{abstract}

\section{Introduction}

Cardiovascular disorders (CVDs) are among the most important and frequent chronic and noncommunicable diseases in the world and contribute to $30 \%$ of mortalities throughout the world [1]. According to the studies, about 14 million people died due to CVDs in 1990 and it is predicted that this measure reaches 25 million in 2020 [2].

Atherosclerosis and its related factors (risk factors) cause coronary artery disease [3]. These risk factors are classified into two groups: noncorrectable, such as age, race, gender, and correctable, such as smoking, hypercholesterolemia, type II diabetes, hypertension, obesity and overweight, sedentary life style, and stress [4]. Identification of these factors can help us develop practical guidelines which can reduce the incidence of CVDs and their mortality and eventual socioeconomic problems [5].

Physical activity is a predictor of CVDs and their mortality [6]. Nowadays overweight and obesity have created an epidemic with an increased tendency to sedentary life [7] which is the most principal cardiovascular risk factor among industrial workers [8].

It is estimated that worldwide prevalence of hypertension is about one billion and it causes approximately 7.1 million deaths per year [9]. According to World Health Organization (WHO), hypertension accounts for $62 \%$ and $49 \%$ of cases of CVD and ischemic heart disease, respectively [10].

Other occupational factors which can increase the risk of CVDs include high workload, shift work, noise, and psychosocial factors $[11,12]$. Some studies have shown that these 
risk factors are not assumed as independent, but they may aggravate the effect of other risk factors [13-15].

Some studies have assessed the cardiovascular risk factors among occupational groups. In a study in China, the most prevalent cardiovascular risk factors in steel workers included hypertension, smoking, overweight, and hypercholesterolemia [16]. In another study in Mexico the prevalence of cardiovascular risk factors (hypercholesterolemia, hypertriglyceridemia, overweight, obesity, and hypertension) in males and females older than 30 years was $13.2 \%$ and $42.2 \%$, respectively [17]. Among bus drivers, obesity, hypertension, hyperlipidemia, and hyperglycemia were the most frequent cardiovascular risk factors [9].

Evaluation of adults' cardiovascular risk factors is an important issue to reduce the frequency of disorders and their complications. Employees as a large and active population in a society are apt to the risk factors of CVDs some of which may be preventable. So in this study we aimed to evaluate the cardiovascular risk factors of workers of tile and ceramic industry which is the main industry in Yazd. We couldnot find another study conducted on tile and ceramic workers regarding cardiovascular risk factors.

\section{Materials and Methods}

In a cross-sectional study from March 2011 till March 2012, 1200 tile and ceramic workers were selected by simple sampling method. There were only 48 females who were excluded from the study due to low sample size. Among males, 77 subjects did not continue the study, so at last the results of physical and lab tests of 1075 workers were evaluated. Workers were selected from different parts of the factory, including grinding, ball mill, forming, glazing and printing, glazemaking, firing, packing, office, service, laboratory, maintenance, forklift driving, and warehouse.

Medical history taking and physical examination were performed by three occupational physicians who were similarly trained for this project. Demographic data (including age, gender, marital status, educational level, and job title) were recorded for each participant.

Individual or family history of CVDs was asked by the physicians. Physical examination included measuring height, weight, and blood pressure. Height was measured in standing neutral position without shoes. Weight was measured by a digital scale (Laica, China) with subjects wearing home clothing without shoes. Waist circumference was measured at $2-3 \mathrm{~cm}$ above the umbilicus. Hip circumference was defined as the greatest diameter between the waist and knee [18]. BMI was calculated by dividing weight (in $\mathrm{Kg}$ ) by the square of height (in $\mathrm{m}$ ). Blood pressure was measured after 10 minutes sitting relaxed by a mercury sphygmomanometer (Richter, Germany).

BMI was categorized according to WHO classification, that is, $\mathrm{BMI}<18.5$ : underweight, $18.5 \leq \mathrm{BMI} \leq 24.9$ : normal, $\mathrm{BMI} \geq 25$ : overweight, $25<\mathrm{BMI} \leq 29.9$ : preobesity, and $\mathrm{BMI} \geq$ 30: obesity [19]. Abdominal obesity was defined as waist to hip ratio $>1$ in males and $>0.8$ in females.

Blood pressure was classified according to the guidelines of European Society of Hypertension and European Society of
TABLE 1: Demographic and descriptive data of all participants.

\begin{tabular}{lc}
\hline Variable & Mean (SD) \\
\hline Age $($ years $)$ & $31.38(6.77)$ \\
Height $(\mathrm{m})$ & $173.60(7.36)$ \\
Weight $(\mathrm{Kg})$ & $76.20(14.19)$ \\
BMI $\left(\mathrm{Kg} / \mathrm{m}^{2}\right)$ & $25.32(4.45)$ \\
SBP $(\mathrm{mmHg})$ & $112.77(9.16)$ \\
DBP $(\mathrm{mmHg})$ & $71.87(5.1)$ \\
FBS $(\mathrm{mg} / \mathrm{dL})$ & $90.23(25.32)$ \\
TC $(\mathrm{mg} / \mathrm{dL})$ & $182.36(64.23)$ \\
TG $(\mathrm{mg} / \mathrm{dL})$ & $149.54(84.49)$ \\
LDL $(\mathrm{mg} / \mathrm{dL})$ & $83.59(37.17)$ \\
HDL $(\mathrm{mg} / \mathrm{dL})$ & $40.90(9.58)$ \\
\hline
\end{tabular}

SBP: systolic blood pressure; FBS: fasting blood sugar; DBP: diastolic blood pressure; TG: triglycerides; LDL: low-density lipoprotein; HDL: high-density lipoprotein; SD: standard deviation.

Cardiology, that is, $\mathrm{SBP}<120$ and $\mathrm{DBP}<80$ : optimal, $120 \leq$ $\mathrm{SBP} \leq 129$ and $80 \leq \mathrm{DBP} \leq 84$ : normal, $130 \leq \mathrm{SBP} \leq 139$ or $85 \leq \mathrm{DBP} \leq 89$ : high normal, and $\mathrm{SBP} \geq 140$ or $\mathrm{DBP} \geq 90$ : hypertension [20].

Blood sampling was performed in the morning with at least 12-hour fasting to measure fasting blood sugar (FBS), total cholesterol (TC), triglyceride (TG), high-density lipoprotein (HDL), and low density lipoprotein (LDL). Blood parameters were analyzed by an autoanalyzer (Hitachi 902). All laboratory tests were performed in a single laboratory.

FBS level was classified based on the recommendations of the American Diabetes Association, that is, FBS < 100: desirable, $100 \leq \mathrm{FBS}<125$ : borderline, and FBS $\geq 126$ : diabetes [21].

Blood lipids level was categorized according to the National Cholesterol Education Program (NCEP), that is, $\mathrm{TG}<150$ : normal, $150 \leq \mathrm{TG}<199$ : borderline, $\mathrm{TG} \geq 200$ : increased. $\mathrm{LDL}<100$ : optimal, $100 \leq \mathrm{LDL} \leq 129$ : desirable, $130 \leq \mathrm{LDL} \leq 159$ : borderline, and $\mathrm{LDL} \geq 160$ : increased.

$\mathrm{HDL} \geq 40$ : desirable, HDL < 40: decreased [22].

Data were analyzed by SPSS (ver. 19) using student's $t$ test and chi square test. An informed consent was obtained from each participant (in Persian). Level of significance was considered to be 0.05 . This study was approved by the Ethics Committee of Shahid Sadoughi University of Medical Sciences.

\section{Results and Discussion}

3.1. Results. Study subjects included 1075 tile and ceramic workers. All participants were males with mean age of $31.38 \pm$ 6.77 years. $78 \%$ of them were married. Table 1 shows demographic data and descriptive statistics of all subjects. Ten participants $(0.9 \%)$ had positive family history for CVDs and 91 participants $(8.5 \%)$ were smokers.

Thirty-four participants $(3.1 \%)$ had completed elementary education and 123 ones (11.5\%) had completed guidance school. In addition, $871(4.4 \%)$ and 48 (81\%) participants were graduated from high school and university, respectively. 
TABLE 2: Frequency distribution of BMI, SBP and DBP, and FBS among all subjects.

\begin{tabular}{lccc}
\hline & Classification & Cut point & No. (\%) \\
\hline \multirow{4}{*}{ BMI } & Underweight & $<18.5$ & $62(5.8)$ \\
& Normal & $18.5-24.9$ & $479(44.6)$ \\
& Overweight & $\leq 25$ & $534(49.6)$ \\
& Preobesity & $25-29.9$ & $376(35.0)$ \\
& Obesity & $\geq 30$ & $158(14.6)$ \\
\hline \multirow{4}{*}{ Abdominal } & Normal & $<1$ in males & $948(88.2)$ \\
& & $<0.8$ in females & \\
& Abnormal & $>1$ in males & $127(11.8)$ \\
& & $>0.8$ in females & \\
\hline \multirow{4}{*}{ Blood pressure } & Optimal & SBP $<120$ & $888(82.6)$ \\
& Normal & SBP 120-129 & $125(11.6)$ \\
& High normal & SBP 120-129 & $32(3.0)$ \\
& Optimal & SBP $\geq 140$ & $30(2.8)$ \\
& Normal & DBP $80-84$ & $59(5.5)$ \\
& High normal & DBP 85-89 & $17(1.6)$ \\
Fugting blood & Hypertension & DBP $\geq 90$ & $22(2.0)$ \\
\hline & Desirable & $<100$ & $926(87)$ \\
& Borderline & $100-125$ & $116(10.9)$ \\
& Increased & $\geq 126$ & $22(2.1)$ \\
\hline
\end{tabular}

Among all subjects, 731 individuals (68\%) had at least one risk factor, and $52 \%, 12 \%, 3 \%$, and $0.7 \%$ had one, two, three, and four risk factors, respectively. Tables 2 and 3 show the frequency distribution of various risk factors.

Table 4 shows the frequency of the presence of risk factors separately in each occupational group. Table 5 shows the anthropometric characteristics of the subjects. Tables 6 and 7 show the classification of the subjects according to BMI and blood pressure, respectively. Classification according to FBS and lipids is presented in Table 8 .

3.2. Discussion. Cardiovascular diseases are among the most important causes of morbidity and mortality in different populations. Sedentary life style is one of the main risk factors of these diseases, so in occupational settings with low activity we expect to find a lot of risk factors, but in industrial settings in which workers are active during work shift, it seems that the frequency of CVD risk factors is low.

The main CVD risk factors include age, race, gender, smoking, hypercholesterolemia, type II diabetes, hypertension, obesity and overweight, sedentary life style, and stress [4]. Some of these risk factors are correctable and if periodically evaluated can be corrected in an early time. During periodic evaluations of workers some features of general health are evaluated as well. So, some of these risk factors can be addressed in occupational health evaluations.

In this study, we assessed the frequency of different CVD risk factors among tile and ceramic workers considering
TABLE 3: Frequency distribution of total cholesterol (TC), triglyceride (TG), high-density lipoprotein (HDL), and low density lipoprotein (LDL) in tile workers.

\begin{tabular}{lcc}
\hline Classification & Cut point & No. $(\%)$ \\
\hline TG-normal & $<150$ & $652(60.7)$ \\
TG-borderline & $150-199$ & $217(20.2)$ \\
TG-increased & $\geq 200$ & $206(19.1)$ \\
\hline TC-normal & $<200$ & $924(85.9)$ \\
TC-borderline & $200-239$ & $133(12.3)$ \\
TC-increased & $\geq 240$ & $18(1.8)$ \\
\hline LDL-optimal & $<100$ & $791(73)$ \\
LDL-desirable & $100-129$ & $229(21.8)$ \\
LDL-borderline & $130-159$ & $44(4.2)$ \\
LDL-increased & $\geq 160$ & $11(1)$ \\
\hline HDL-desirable & $\geq 40$ & $555(51.6)$ \\
HDL-decreased & $<40$ & $520(48.4)$ \\
\hline
\end{tabular}

different job titles in this industry. This study identified a relatively active and young population with a high prevalence of cardiovascular risk factors.

Although overweight and obesity were not included in the general CVD risk prediction model of the Framingham Heart Study [23], the impact of body mass index on the risk of CVD incidence has been proved by many studies. European guidelines on cardiovascular disease prevention suggested that avoiding overweight or reducing the existing overweight is important in patients with established CVD as well as in high risk people [5].

In our study, overweight was observed in about half of the subjects and obesity in about $15 \%$ of them, which is very high if we consider that we have evaluated a relatively young and active population, because they were industrial workers who are completely active at least for 8 hours in their working shift, although this frequency was lower than those of Yazd urban population with $16.5 \%$ obesity [24], Brazilian workers with $68 \%$ overweight [8], bus drivers with $76.5 \%$ overweight [9], and workers of Isfahan electricity company with $60.3 \%$ overweight [25]. In other studies also overweight and obesity were CVD risk factors $[26,27]$, but in a study among health care workers in Singapore BMI was not an important risk factor [28].

The mean BMI in this study was similar to that in Tehran urban population $(25.7 \%)$, but the frequency of overweight was lower in that study (40\%) [29]; although these studies have been performed in different populations and different times, so it is possible that their risk factors are different. Abdominal obesity in this study was lower than that in general population of Yazd [24], although in the study on general population most cases of abdominal obesity were females and our study consisted of males only.

Hypertension as one of the other important risk factors of CVDs was lower in our study compared to 27.59\% in Yazd adult population [24] and $20.4 \%$ in Tehran adult population [29]. This measure in tile workers was lower than those of Isfahan electricity company (16\%) [25], and bus drivers in Brazil (35\%) [9], and health care workers of Taiwan (29\%) [15]. This low frequency of hypertension in this occupational 
TABLE 4: Frequency of the presence of risk factors in different occupational groups.

\begin{tabular}{|c|c|c|c|c|c|c|c|}
\hline \multirow{2}{*}{ Job title } & \multicolumn{2}{|c|}{ Hypertension } & \multirow{2}{*}{ Overweight } & \multirow{2}{*}{ Increased FBS } & \multirow{2}{*}{ Increased TG } & \multirow{2}{*}{ Increased LDL } & \multirow{2}{*}{ Decreased HDL } \\
\hline & Systolic & Diastolic & & & & & \\
\hline 1 & 6.5 & - & 16 & - & 9.7 & - & 51.6 \\
\hline 2 & 1.6 & 1.6 & 8.2 & 1.6 & 19.7 & - & 47.5 \\
\hline 3 & 1.8 & 3.6 & 12.7 & - & 14.5 & 3.6 & 50.9 \\
\hline 4 & 2.4 & 2.4 & 20 & 1.6 & 18.5 & 1.6 & 48.4 \\
\hline 5 & 6.1 & 12.1 & 18.2 & - & 24.2 & 3 & 54.5 \\
\hline 6 & - & 1.1 & 20.5 & 2.3 & 22.7 & 9.1 & 43.2 \\
\hline 7 & 5.5 & 3 & 10.3 & 0.6 & 12.7 & 1.2 & 55.2 \\
\hline 8 & - & - & 13 & 3.8 & 15.2 & 2.2 & 55.2 \\
\hline 9 & - & 3.7 & 7.4 & - & 14.8 & 7.4 & 51.9 \\
\hline 10 & 8.3 & - & 12.5 & 4.2 & - & 12.5 & 50.0 \\
\hline 11 & 6.6 & 2.6 & 10.5 & 2.6 & 23.7 & 2 & 50.0 \\
\hline 12 & 4.4 & 4.4 & 22.2 & - & 26.7 & 6.7 & 42.2 \\
\hline 13 & - & - & 32.6 & 9.3 & 41.9 & 14 & 34.9 \\
\hline
\end{tabular}

1: grinding, 2: ball mill, 3: forming, 4: glazing and printing, 5: glaze-making, 6: firing, 7: packing, 8: office, 9: service, 10: laboratory, 11: maintenance, 12: forklift driving, and 13: warehouse.

TABLE 5: Anthropometric and clinical characteristics of the population.

\begin{tabular}{lcccc}
\hline Variable & Number & Minimum & Maximum & Mean $(\mathrm{SD})$ \\
\hline Age $($ years $)$ & 1075 & 20.00 & 67.00 & $31.38(6.77)$ \\
Height $(\mathrm{m})$ & 1075 & 139.00 & 198.00 & $173.60(7.36)$ \\
Weight $(\mathrm{Kg})$ & 1075 & 41.00 & 130.00 & $76.20(14.19)$ \\
BMI $\left(\mathrm{Kg} / \mathrm{m}^{2}\right)$ & 1075 & 16.28 & 42.17 & $25.32(4.45)$ \\
SBP $(\mathrm{mmHg})$ & 1073 & 75 & 175 & $112.77(9.16)$ \\
DBP $(\mathrm{mmHg})$ & 1073 & 50 & 110 & $71.87(5.1)$ \\
FBS $(\mathrm{mg} / \mathrm{dL})$ & 1064 & 56 & 375 & $90.23(25.32)$ \\
TG $(\mathrm{mg} / \mathrm{dL})$ & 1066 & 21 & 739 & $149.54(84.49)$ \\
LDL $(\mathrm{mg} / \mathrm{dL})$ & 1051 & 10 & 657 & $83.59(37.17)$ \\
HDL $(\mathrm{mg} / \mathrm{dL})$ & 1059 & 26 & 174 & $40.90(9.58)$ \\
\hline
\end{tabular}

SBP: systolic blood pressure; FBS: fasting blood sugar; DBP: diastolic blood pressure; TG: triglycerides; LDL: low-density lipoprotein; HDL: high-density lipoprotein; SD: standard deviation.

TABLE 6: Classification of the population based on body mass index.

\begin{tabular}{lcc}
\hline Classification & Cutoff point & Number (\%) \\
\hline Underweight & $<18.5$ & $62(5.8)$ \\
Normal & $18.5-24.9$ & $479(44.6)$ \\
Overweight & $25-29.9$ & $376(35.0)$ \\
Obesity & $\geq 30$ & $158(14.6)$ \\
\hline
\end{tabular}

group can be explained by their younger age compared to that of Yazd adult population, and their lower job stress compared to those of HCWs, bank workers, and managers [26, 27].

Frequency of abnormal FBS in this study was lower than those of Yazd urban population [24], Tehran general population [29], Polish managers [26], and Indian bankers [27]. This difference can also be explained by lower age and higher activity of our samples, although this measure was higher than that of HCWs in Nkombua study [30].
TABLE 7: Classification of the population based on systolic and diastolic blood pressure.

\begin{tabular}{lcc}
\hline Classification & Cut point & No. (\%) \\
\hline Optimal & SBP $<120$ & $886(82.6)$ \\
Normal & SBP 120-129 & $125(11.6)$ \\
High normal & SBP 120-129 & $32(3.0)$ \\
Hypertension & SBP $\geq 140$ & $30(2.8)$ \\
\hline Optimal & DBP $<80$ & $975(90.9)$ \\
Normal & DBP 80-84 & $59(5.5)$ \\
High normal & DBP 85-89 & $17(1.6)$ \\
Hypertension & DBP $\geq 90$ & $22(2.0)$ \\
\hline
\end{tabular}

TABLE 8: Classification of the population based on FBS and lipids.

\begin{tabular}{lcc}
\hline Classification & Cut point & No. $(\%)$ \\
\hline FBS-desirable & $<100$ & $926(87)$ \\
FBS-borderline & $100-125$ & $116(10.9)$ \\
FBS-increased & $\geq 126$ & $22(2.1)$ \\
\hline TG-normal & $<150$ & $643(60.3)$ \\
TG-borderline & $150-199$ & $217(20.4)$ \\
TG-increased & $\geq 200$ & $206(19.3)$ \\
\hline LDL-optimal & $<100$ & $767(73)$ \\
LDL-desirable & $100-129$ & $229(21.8)$ \\
LDL-borderline & $130-159$ & $44(4.2)$ \\
LDL-increased & $\geq 160$ & $11(1)$ \\
\hline HDL-desirable & $\geq 40$ & $520(50.9)$ \\
HDL-decreased & $<40$ & $520(49.1)$ \\
\hline
\end{tabular}

The frequency of smokers in this study was lower than those of Yazd urban population [24], Prabhakaran et al. study in India [31], Bugajska et al. study in Poland [26], and some other studies $[8,25,29]$, although we are not sure about this issue that how much we can trust workers' self-report. 
In health care workers smoking was less frequent than in our population $[28,30]$ which can be explained by their higher social and educational level.

Mean TG level was similar to those of industrial workers in India [31] and bus drivers in Brazil [9], although it was lower than those of managers in Poland [26] and electricity company workers [25], which can be again explained by their higher level of activity.

Hypertriglyceridemia in this study was lower than those of Indian industrial workers [31], Isfahan electricity company workers [25], and Kashan drivers [32], which again can be explained by higher level of activity in this occupational group. This measure was higher in our samples compared to HCWs in Singapore [28] and Brazilian workers [8].

Other risk factors such as increased LDL and cholesterol were also different in this study from other studies on different jobs [24, 26, 27, 29, 31].

The most frequent risk factor in this study was abnormal BMI; Low HDL and increased TG were in the 2nd and 3rd orders. Overweight was most commonly observed in warehouse workers which can be explained by their lower level of activity compared to other workers. Overweight in office workers, who have sedentary work as well, was lower than in warehouse workers, which is probably due to their higher social level and different nutrition style.

\section{Conclusions}

This study showed a relatively high prevalence for CVD risk factors among tile and ceramic workers. Low HDL, high TG, and overweight were the most frequent risk factors in this population.

\section{Acknowledgments}

The authors are grateful to Behrouz Moghbel and Mahdi Davari for their kind collaboration in this project.

\section{References}

[1] “The global burden of disease: 2004 update," Tech. Rep., WHO, Geneva, Switzerland, 2008.

[2] B. Neal, N. Chapman, and A. Patel, "Managing the global burden of cardiovascular disease," European Heart Journal, vol. 4, no. 6, supplement, pp. F2-F6, 2002.

[3] G. F. Gensini, M. Comeglio, and A. Colella, "Classical risk factors and emerging elements in the risk profile for coronary artery disease," European Heart Journal, vol. 19, pp. A53-A61, 1998.

[4] J.-P. Després, B. J. Arsenault, M. Côté, A. Cartier, and I. Lemieux, "Abdominal obesity: the cholesterol of the 21st century?" The Canadian Journal of Cardiology, vol. 24, pp. 7D-12D, 2008.

[5] G. De Backer, E. Ambrosioni, K. Borch-Johnsen et al., "European guidelines on cardiovascular disease prevention in clinical practice: third joint task force of European and other societies on cardiovascular disease prevention in clinical practice (constituted by representatives of eight societies and by invited experts)," European Journal of Cardiovascular Prevention and Rehabilitation, vol. 10, no. 4, pp. S1-S10, 2003.
[6] J. D. Eicher, C. M. Maresh, G. J. Tsongalis, P. D. Thompson, and L. S. Pescatello, "The additive blood pressure lowering effects of exercise intensity on post-exercise hypotension," American Heart Journal, vol. 160, no. 3, pp. 513-520, 2010.

[7] "Diet, nutrition and the prevention of chronic diseases. Report of a Joint WHO/FAO Expert Consultation," Tech. Rep. 916, World Health Organization, Geneva, Switzerland, 2003.

[8] R. S. L. Cassani, F. Nobre, A. Pazin Filho, and A. Schmidt, "Prevalence of cardiovascular risk factors in a population of Brazilian industry workers," Arquivos Brasileiros de Cardiologia, vol. 92, no. 1, pp. 16-22, 2009.

[9] R. P. Hirata, L. M. M. Sampaio, F. S. S. Leitmo Filho et al., "General characteristics and risk factors of cardiovascular disease among interstate bus drivers," The Scientific World Journal, vol. 2012, Article ID 216702, 7 pages, 2012.

[10] World Health Organization, "World health report 2002. Reducing risks, promoting healthy life," Tech. Rep., World Health Organization, Geneva, Switzerland, 2002.

[11] M. Nurminen and A. Karjalainen, "Epidemiologic estimate of the proportion of fatalities related to occupational factors in Finland," Scandinavian Journal of Work, Environment \& Health, vol. 27, no. 3, pp. 161-213, 2001.

[12] Y. X. Yan, J. Dong, Y. Q. Liu et al., "Association of suboptimal health status and cardiovascular risk factors in urban Chinese workers," Journal of Urban Health, vol. 89, no. 2, pp. 329-338, 2012.

[13] W. J. Hwang and O. Hong, "Work-related cardiovascular disease risk factors using a socioecological approach: implications for practice and research," European Journal of Cardiovascular Nursing, vol. 11, no. 1, pp. 114-126, 2012.

[14] M. G. Kang, S. B. Koh, B. S. Cha, J. K. Park, S. K. Baik, and S. J. Chang, "Job stress and cardiovascular risk factors in male workers," Preventive Medicine, vol. 40, no. 5, pp. 583-588, 2005.

[15] C.-M. Lin and C.-Y. Li, "Prevalence of cardiovascular risk factors in Taiwanese healthcare workers," Industrial Health, vol. 47, no. 4, pp. 411-418, 2009.

[16] J. Ji, E. Pan, J. Li et al., "Classical risk factors of cardiovascular disease among Chinese male steel workers: a prospective cohort study for 20 years," BMC Public Health, vol. 11, article 497, 2011.

[17] M. G. Fanghänel-Salmón, M. J. Padilla-Retana, M. L. SánchezReyes, M. E. M. Torres-Acosta, M. L. Cortinas-López, and M. J. Espinosa-Campos, "Prevalence of coronary artery disease risk factors in workers at the general hospital of Mexico of the ministry of health," Endocrine Practice, vol. 3, no. 5, pp. 313-319, 1997.

[18] "Obesity: preventing and managing the global epidemic," Tech. Rep. 894, WHO Consultation, Geneva, Switzerland, 2000.

[19] World Health Organization, "Global database on body mass index," Tech. Rep., 2009.

[20] G. Mancia, G. De Backer, A. Dominiczak et al., "2007 ESHESC Practice Guidelines for the Management of Arterial Hypertension: ESH-ESC Task Force on the Management of Arterial Hypertension," Journal of Hypertension, vol. 25, no. 9, pp. 17511762, 2007.

[21] Association AD, "American diabetes association clinical practice recommendations," Tech. Rep., American Diabetes Association, 2005.

[22] S. M. Grundy, D. Becker, L. T. Clark et al., "Detection, evaluation, and treatment of high blood cholesterol in adults (Adult Treatment Panel III)," Circulation, vol. 106, no. 25, pp. 31433421, 2002. 
[23] R. B. D’Agostino Sr., R. S. Vasan, M. J. Pencina et al., "General cardiovascular risk profile for use in primary care: The Framingham Heart Study," Circulation, vol. 117, no. 6, pp. 743-753, 2008.

[24] S. M. Namayandeh, S. M. Sadr, Z. Ansari, and M. Rafiei, "A cross-sectional study of the prevalence of coronary artery disease traditional risk factors in Yazd urban population, Yazd healthy heart project," Iranian Cardiovascular Research Journal, vol. 5, no. 1, pp. 7-13, 2011.

[25] A. Khaledifar, A. Bahonar, M. Asadilari et al., "Risk factors of cardiovascular diseases in a worker population in Isfahan province (Isfahan Electricity Production and Distribution Company)," ARYA Atherosclerosis, vol. 7, supplement, pp. S82S87, 2012.

[26] J. Bugajska, J. M. Michalak, A. Jedryka-Góral, A. Sagan, and M. Konarska, "Coronary heart disease risk factors and cardiovascular risk in physical workers and managers," International Journal of Occupational Safety and Ergonomics, vol. 15, no. 1, pp. 35-43, 2009.

[27] A. K. Sarkar, S. K. Adak, P. Bhattacharya, P. Marimuthu, R. N. Chaudhuri, and K. K. Banerjee, "Risk assessment of cardiovascular diseases among bank employees—a biochemical approach," Occupational Medicine, vol. 49, no. 5, pp. 313-318, 1999.

[28] L. Leong and S. Chia, "Prevalence of cardiovascular risk factors among healthcare staff in a large healthcare institution in Singapore," Singapore Medical Journal, vol. 53, no. 8, pp. 517-521, 2012.

[29] F. Azizi, M. Rahmani, H. Emami et al., "Cardiovascular risk factors in an Iranian urban population: Tehran lipid and glucose study (phase 1)," Sozial- und Praventivmedizin, vol. 47, no. 6, pp. 408-426, 2002.

[30] L. Nkombua, "Risk factors for cardiovascular disease in workers at a district hospital: brief report," Southern African Journal of Epidemiology and Infection, vol. 27, no. 1, pp. 38-39, 2012.

[31] D. Prabhakaran, P. Shah, V. Chaturvedi, L. Ramakrishnan, A. Manhapra, and K. S. Reddy, "Cardiovascular risk factor prevalence among men in a large industry of northern India," National Medical Journal of India, vol. 18, no. 2, pp. 59-65, 2005.

[32] H. R. Saberi, A. R. Moravveji, E. Fakharian, M. M. Kashani, and A. R. Dehdashti, "Prevalence of metabolic syndrome in bus and truck drivers in Kashan, Iran," Diabetology and Metabolic Syndrome, vol. 3, no. 1, article 8, 2011. 


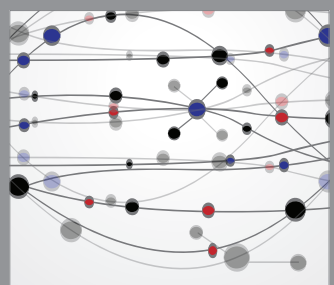

The Scientific World Journal
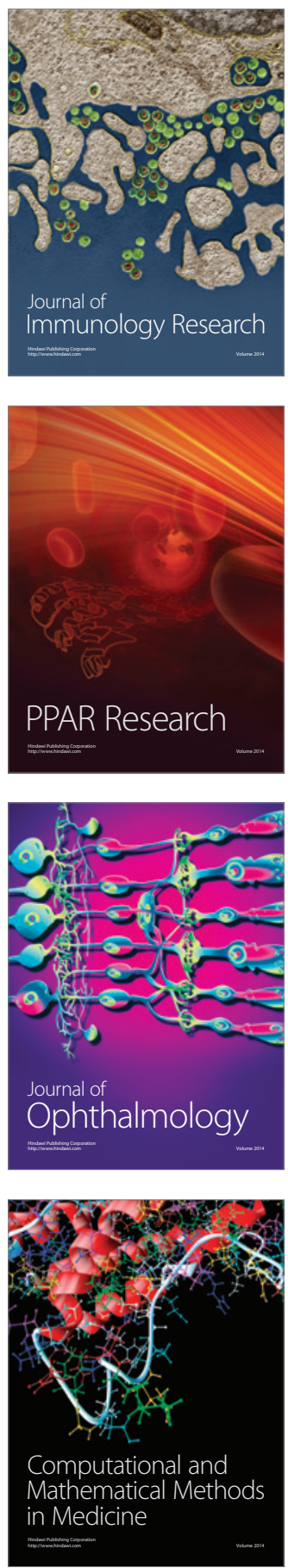

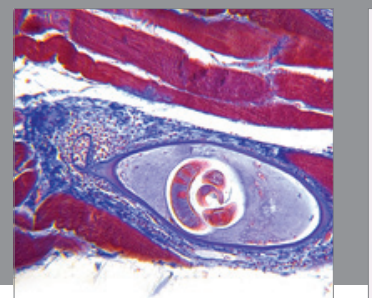

Gastroenterology

Research and Practice
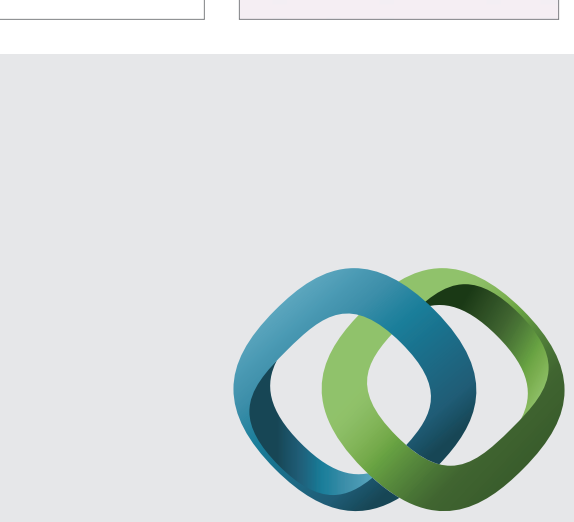

\section{Hindawi}

Submit your manuscripts at

http://www.hindawi.com
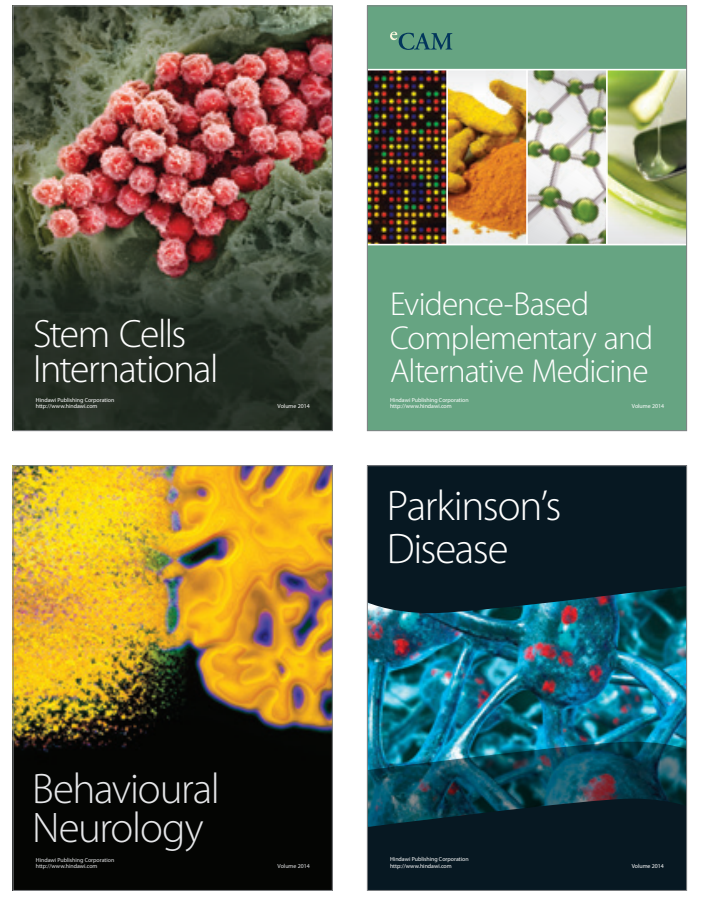
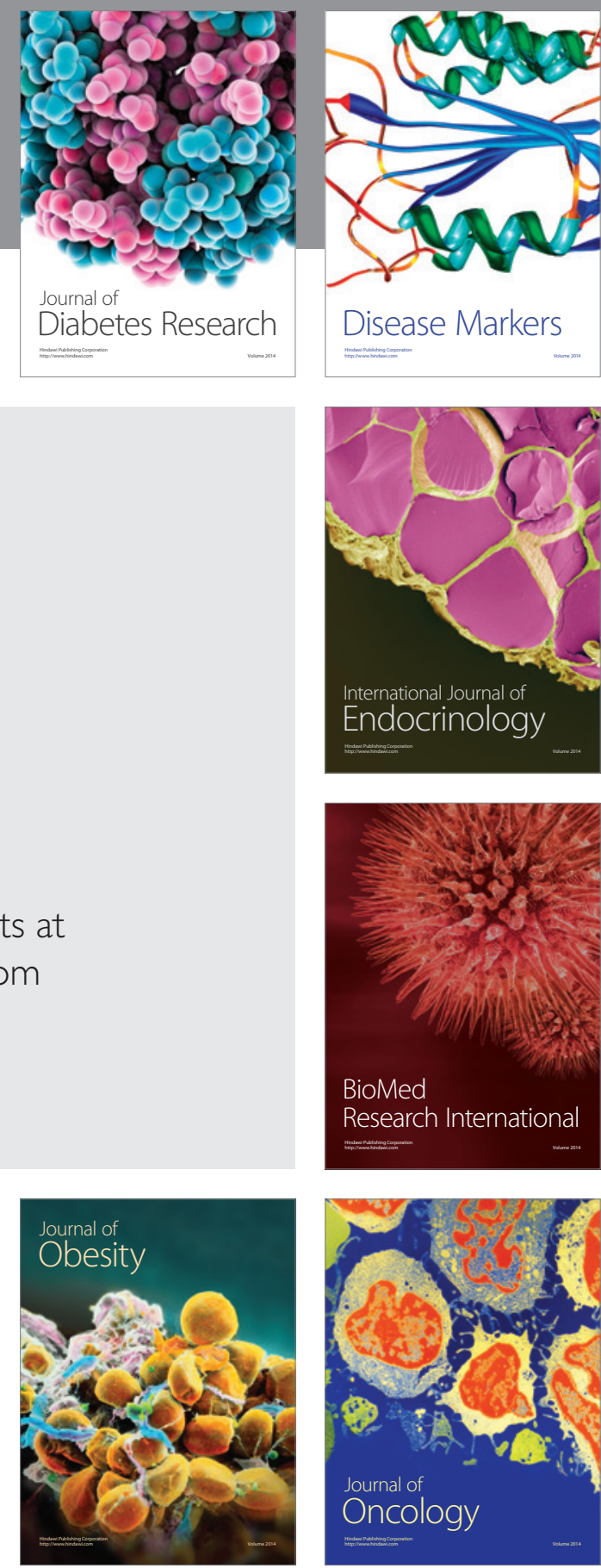

Disease Markers
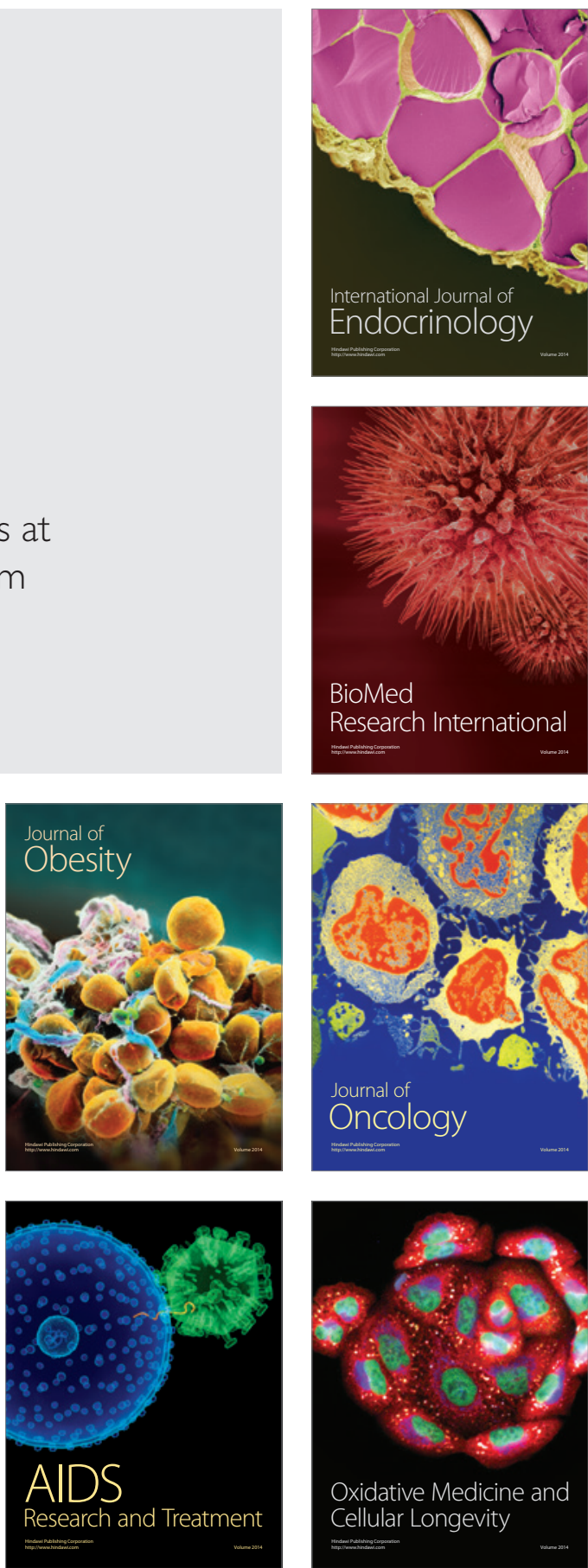